\title{
Need For Quality Interventions in Vocational Education in India
}

\author{
S. Nayana Tara, and N.S. Sanath Kumar
}

\begin{abstract}
The paper focusses on the need for quality in vocational training institutions in India. According to the National Policy on Skill Development and Entrepreneurship 2015 (Government of India, 2015) the number of young people who enter the work force every year is estimated to be 26 million. Assuming an average labour participation rate of $90 \%$ (male) and $30 \%$ (female), at least 16 million persons will enter workforce and they all, except those opting for higher education, need to acquire skills which match high quality standards in order to compete, and excel at international levels. The present paper discusses the need for integrating Total Quality Management (TQM) principles in effective functioning of Industrial Training Institutes (ITI). Findings of a study of ITIs in the Southern state of Karnataka, India, is presented which, in the main, highlight the lack of application of quality principles in these institutions and discusses an appropriate model of TQM which could be applied. Further, a need for research in quality implications for ITI s and crosscountry collaboration are highlighted.
\end{abstract}

Key words-- Vocational Education, Quality, ITI s

\section{INTRODUCTION}

Proficiency in skills and knowledge acquisition are the driving forces of economic growth and social development for any country. Countries with higher and better levels of skills adjust more effectively to the challenges and opportunities of world of work. India is one of the youngest nations in the world with more than $62 \%$ of its population in the working age group (15-59 years), and more than 54\% of its total population below 25 years of age. Its population pyramid is expected to 'bulge' across the age-group of 15-59 years over the next decade. It is further estimated that the average age of the population in India by 2020 will be 29 years as against 40 years in USA, 46 years in Europe and 47 years in Japan. In fact, during the next 20 years the labour force in the industrialized world is expected to decline by $4 \%$, while in India it will increase by $32 \%$ (National Higher Education Mission, Ministry of Human Resource Development, 2013). To reap this demographic dividend which is expected to last for next 25 years, India needs to equip its workforce with employable skills and knowledge so that they can contribute substantively to the economic growth of the country.

S. Nayana Tara, Professor, Centre For Public Policy, IIMB N.S. Sanath Kumar, Consultant, Centre For Public Policy, IIMB
Realizing this need, an exclusive Ministry for Skill Development and Entrepreneurship has been set up in November 2014 to give fresh impetus to the Skill India agenda and help create an appropriate ecosystem that facilitates imparting employable skills to its growing workforce over the next few decades. (Government of India, National Policy for Skill Development and Entrepreneurship 2015, New Delhi)

The Policy stated, inter alia, that access to training should be available to all, particularly those at the bottom of the pyramid. It said that the government should complement private sector initiatives in skill development and emphasizes the need for short-term, industry-relevant courses. Potentially, the target group for skill development comprises all those in the labor force, including those entering the labor market for the first time (12.8 million annually), those employed in the organized sector (26.0 million) and those working in the unorganized sector (433 million) in 2004-05. The current capacity of the skill development programs is 3.1 million. According to a skill gap study conducted by National Skill Development Corporation (NSDC) over 2010-2014, which indicates that there is an additional net incremental requirement of 109.73 million skilled manpower by 2022 in twenty four key sectors.

The poignant goal of the present government, 'Make in India' which includes major new initiatives designed to facilitate investment, foster innovation, protect intellectual property, and build best-in-class manufacturing infrastructure (www.makeinindia.gov.in/) further necessitates the revamping of the educational system through institutionalizing professionally planned skill development education programmes at the primary and upper primary level itself. Overarching these efforts will invariably be a clear focus on ensuring quality in planning and implementation along with a robust monitoring of tasks taken on hand. (Tara \& Sanath Kumar : 2016)

However, leveraging this 'demographic dividend' is easier said than done on account of the poor level of skills possessed by the vast majority of those joining the workforce each year due to a variety of reasons including high rates of school dropouts, inadequate skills training capacity, a negative perception around skilling, and low employability of even those holding professional qualifications, such as degrees in different engineering disciplines. Overarching these factors, and as an effect, is the low priority given to accomplishing high quality among the skilled workforce. The concept of quality management implies creating a set of policies and actions with the support of the direction which facilitates mobilization of the vocational training institutions towards a 
quality culture that goes beyond certification process in itself. It implies a commitment on the part of the entire organization, to a new way of doing things in order to achieve objectives from the beginning. An effort is made in this paper to discuss and highlight the need for quality interventions in one of the country's major training institution, the Industrial Training Institutes (ITI).

\section{INDUSTRIAL TRAINING INSTITUTES (ITI)}

Industrial Training Institutes (ITI s) were established in the country which is the major training ground for skilled manpower. At present there are a total of 11,964 (Govt. 2284 + Pvt. 9680) in the country (Government of India, Ministry of Skill Development and Entrepreneurship (www.dget.nic.in/content/institute/key-statistics.php).

Vocational Training is imparted in 126 trades (73 Engineering+ 48 Non- Engineering +05 exclusively for visually impaired) of duration 1-2 years. National Trade Certificate - Nationally \& internationally recognized under the aegis of National Council for Vocational Training (NCVT) is awarded to successful trainees. While the Central Government is entrusted with responsibility of framing overall policies, norms \& standards \& examination for vocational training while day-to-day administration of Industrial Training Institutes rests with the State Governments/ Union Territories Administrations.

Towards producing technicians of world standard, the Government of India has launched a programme of upgrading 500 ITI s during 2005-06 at the rate of 100 ITI s into Centers of Excellence (COE) each year. The main objectives of this programme is to:

$>$ Produce high quality craftsmen from publicly funded ITI s

$>$ Enhance knowledge and training skills of ITI instructors and trainers

$>$ Promote innovations and

$>$ Bring about systemic reforms

The salient features of the scheme include introduction of multi-skilling courses under Broad Based Basic Training (BBBT) of one year duration followed by advanced/specialized modular courses through an industrywise cluster approach with multi-entry and multi-exit provisions. Establishing Public Private Partnership in the form of Institute Management Committees (IMCs) is envisaged to ensure greater and active involvement of industry in various aspects of training.

A major challenge is to facilitate ITI s to keep pace with the fast growing technological demands for industry and the expanding universe of knowledge in a globalized scenario. Further, such an attempt to enhance the quality of training and training infrastructure through improved design and delivery system would have positive employment outcomes of graduates from the vocational training system especially in the existing industrial and economic scenarios where considerably high demand for professional technicians exist.

Against this backdrop, a study was carried out to assess the functioning of selected COEs among Industrial Training
Institutes (ITI) located in the state of Karnataka, India. The major findings of the study were the following:

1. Lack of awareness regarding its uniqueness and usefulness of the programme among parents, students and industry has resulted in very poor demand

2. The short duration of two months for each module in the BBBT component has put in a huge amount of pressure on students to perform in the examination.

3. Interestingly, older COEs as compared to recent ones were relatively well equipped.

4. Most of the training instructors reported that the training they have received was quite beneficial and opined that there is an urgent need for participating in such programmes on a regular manner in order to keep pace with the latest advances in the industrial sectors.

5. Currently, there are no career growth opportunities for trainers/instructors, which is a de-motivating factor.

6. The role of IMCs appeared to be weak in many sample COEs and limited to only a few issues such as financial approvals, procurement related matters and to some extent student placements. IMCs appeared to have only advisory role without adequate powers and minimal roles in the areas of staff training, constant interaction with industry to generate demand for COE students, instilling confidence among students through regular interaction with them and providing all necessary support and guidance.

7. The major problems experienced by students in the course of their study included comprehension difficulties due to poor English knowledge and communication skills, difficulty in coping with short duration BBBT modules, no or inadequate stipend, lack of hostel facilities and inadequate transport

8. Quality is measured in the marks obtained by the students while no other quality indictor is in use.

9. All the respondents reported that there has not been any support from Quality Council of India which is expected to provide guidance and assistance in enhancing the quality of the programme.

10. Inadequate training and other infrastructure facilities and their poor maintenance were reported by a significant proportion of the respondents covered

11. A large amount of vacancies of teaching staff that are not filled easily is a major challenge among most of the institutions as inordinate administrative delays in recruitment by the department was reported

12. Lack of autonomy in decision making with respect to recruitment, salaries, infrastructure development and curriculum design was reported by all the respondents.

\section{DISCUSSION}

Emerging out of the findings is that despite several efforts of up-gradation, ITIs have not been able to meet the expected quality standards. Against this backdrop, it is of highest importance to address the issue of quality of vocational training imparted to the students in vocational training institutes, more precisely in the ITI s. The products that come out of these institutions go into the world of work and hence it 
is imperative that the quality of inputs provided to those students must be of high caliber.

The concept of quality management implies creating a set of policies and actions with the support of the direction which facilitates the mobilization of the ITIs towards a quality culture that goes beyond mere certification process in itself. It implies a commitment to a new way of doing things in order to achieve objectives from the beginning. This commitment involves the whole organization. The quality problem stems out of the twin dimensions, viz., (a) those trained do not possess the competencies for employability(either core or soft skills) and (b) there is a mismatch between what is demanded and the skills supplied (Mehrotra et. al. : 2014).

It is interesting to note that several attempts are being made to accomplish quality standards through establishment of National Vocational Quality Framework (NVQF), Quality Council of India (QCI) among others. Further, the Industry has partnered with the Government through National Skill Development Corporation (NSDC) and Sector Skill Councils (SSCs). With the help of Industry, 33 SSCs have developed 1661 Qualification Packs (QPs) covering 4420 unique National Occupation Standards (NOSs). The industry is thus being roped in to help in creating curriculum, training of the trainers and most importantly supporting apprenticeship in the country. However, there has been some reluctance from the Industry in providing a wage differential for skilled workers, leading to low absorption of skilled manpower. The Industry needs to be educated on the benefits of employing a skilled workforce and the difference which skilled workers bring in terms of productivity and efficiency versus an unskilled worker (Interview with Sri S.Ramadorai, former president of National Skill Development Corporation, Government of India in Tara \& Sanath Kumar, Skill Development in India, IIMB Management Review, (2016).

In order to address the growing international demands, national education and training systems are required to a) adopt a broader mandate; $b$ ) have a global vision; and c) act locally. This will entail stronger alliances and increased cooperation with the various stakeholders, including governmental institutions, VET providers and their staff, employers' associations and trade unions. However, many countries have separate education systems and training systems that for generations have operated in relative isolation from one another. There are wide variations between the two sectors in terms of a) their different cultures, governance, finance and accountability; and b) their standards, expectations and ways of measuring learner progress. There is a growing movement by countries to adopt quality-focused VET strategies that rely on strong partnerships with stakeholders in order to make data-informed decisions about identified needs and expectations. (Maria Emília Galvão, Making the Case for Vocational Education and Training Improvement: Issues and Challenges (http://www.etf.europa.eu/webatt.nsf/0/270970490A6E9327C 1257CA800407038/\$file/Quality\%20assurance\%20in\%20VE T.pdf) accessed on 24/10/2016
When vocational education provided in Germany is taken into consideration, the very system of Vocational Education and Training (VET) is given highest importance and is highly evolved. According to Sondermann (Ministerial Director, Head of vocational training directorate) "the vocational education and training system in Germany imparts high quality occupational competencies and vocational qualifications. High transition rates into labor market and low youth unemployment by international comparison underscore the significance of the vocational education of the German employment system." According to Dr. Scheffler (Ministerial Director, Chair of vocational education subcommittee), "the development of a European and subsequently, a German qualification framework is an essential foundation if cooperation in the field of vocational education up to the year 2020 is to be based on reliable instruments". Since India has developed a National Vocational Qualification Framework (NVQF), it would be most ideal for Indian and German partners work together to establish quality standards of vocational education being offered, especially in ITI $s$ as the students will be transiting into the world of work. This, in an internationally competitive training environment, implementation of TQM in VOC can provide a comparative advantage in preparing the quality workforce required for micro and macro- economic reforms. The vocational training institutions that are quality driven will foster innovation and improvement and thus can have a strategic advantage in the provision of quality training.

\section{REFERENCES}

[1] Director General of Employment and Training (DGET) (2016). Key Statistics. Brief note about Industrial Training Institutes. Online: http://dget.nic.in/content/institute/key-statistics.php

[2] Government of India (2009). National Skill Development Policy 2009. (http://skilldevelopment.gov.in/assets/images/NationalSkillDevelopmen tPolicyMar09.pdf)

[3] National Skill Development Corporation, District-wise Skill Gap Study for the State of Punjab, (2012-17 and 1017-22), New Delhi 2013 (http://www.nsdcindia.org/sites/default/files/files/punjab-sg-report.pdf)

[4] Maria Emília Galvão, Making The Case For Vocational Education And Training Improvement: Issues And Challenges, European Training Foundation,2014.

(http://www.etf.europa.eu/webatt.nsf/0/270970490A6E9327C1257CA8 00407038/\$file/Quality\%20assurance\%20in\%20VET.pdf)

[5] Mehrotra, S. (ed.), India's Skills Challenge: reforming vocational education and training to harness the demographic dividend. New Delhi: Oxford University Press

[6] Tara, Nayana \& Sanath Kumar, Primary and Upper Primary (1-8) Education: Initiative for the World of Work at the Primary and Upper Primary Education in India, in Pilz, Matthias (ed) India: Preparation for the World of Work- Education System and School to Work Transition, Springer VS, Wiesbaden 2016

[7] Tara Nayana \& Sanath Kumar, Skill Development in India, IIMB Management Review, 28, 235-243, December2016

Author holds a doctorate in Education and is a Professor in the Centre for Public Policy, Indian Institute of Management, Bangalore, India 